\title{
Triaged treatment-based conventional weapon combat wound classification code design and injury spectrum statistical analysis
}

BO PENG

Institute of health service and transfusion medicine, Academy of military medical sciences

Shuo Liu

Institute of health service and transfusion medicine

Fei Pan

Chinese PLA General Hospital

Zhen He

Institute of health service and transfusion medicine

Tan-shi Li ( $D$ li_tanshi@163.com )

Research

Keywords: combat wound classification, injury site, complications, ranking

Posted Date: May 7th, 2020

DOI: https://doi.org/10.21203/rs.3.rs-25460/v1

License: (c) (1) This work is licensed under a Creative Commons Attribution 4.0 International License.

Read Full License

Version of Record: A version of this preprint was published at Military Medicine on November 1st, 2020.

See the published version at https://doi.org/10.1093/milmed/usaa221. 


\section{Triaged treatment-based conventional weapon combat wound}

\section{2 classification code design and injury spectrum statistical analysis}

3 Bo Peng ${ }^{1}$ and Shuo Liu ${ }^{1}$, Fei Pan ${ }^{2}$, Zhen $\mathrm{He}^{1}$, Tan-shi $\mathrm{Li}^{2 *}$

4 1. Institute of Health Service and Transfusion Medicine, Academy of Military

5 Medical Sciences

6 2. The first medical center of Chinese PLA general hospital

7 *Correspondent: li_tanshi@163.com

8 ABSTRACT: Purpose: To provide evidence for the rapid and efficient classification of combat casualties

9 while simultaneously determining the types of high-incidence fatal injuries that require emergency

10 treatment to support the triage of combat wounds in mass casualty situations. Methods: The three-tiered

11 treatment echelon consisting of battlefield on-site first aid, emergency treatment, and early treatment was

12 used to design an expanded combat wound classification code system according to the differential needs

13 of combat wound treatment. Three dimensions of evaluation indicators consisting of likelihood, importance,

14 and suitability were established and an optimized quasi-HHI index was used for the normalization and

15 ranking of expert survey results. Results: We obtained exhaustive combinations from the massive number

16 of combat wound factors in combat wound classification codes, constructed injury spectrum frameworks

17 within the different treatment echelons, and identified high-incidence fatal injuries in different treatment

18 echelons. Conclusions: Our combat wound classification codes achieved good results in terms of having

19 higher classification speed and accuracy than traditional methods. The high incidence fatal injuries

20 identified by the constructed combat wound spectrum can provide guidance and support when used for the

21 improvement of treatment techniques and upgrading equipment in the Chinese People's Liberation Army.

22 Keyword: combat wound classification, injury site, complications, ranking 


\section{1. BACKGROUND}

24 Combat wound classification codes have great significance for the timely and accurate assessment of the

25 severity of injury of casualties by helping to standardize combat wound treatment, improve treatment

26 quality, and reduce the rates of mortality and disability. Currently, there are two main casualty classification

27 standards used within the Chinese People's Liberation Army (PLA). The first is the 2006 Combat Wound

28 Treatment Guidelines and the existing combat wound classification method for injury ${ }^{\mathbf{1}, 2 \mathbf{1}}$. The second is

29 the 2007 GJB 6032-2007 Combat Wound Classification and Determination Criteria in the Military

30 Standards ${ }^{\mathbf{L} 3 \mathbf{1}}$. These two standards are mainly used at the battlefield on-site stage for the preliminary

31 assessment of injury severity and their content is similar. Combat wound descriptions were divided by

32 injury site, injury category, injury type, and injury severity, for a total of 37 data items. The main problems

33 are insufficient degree of refinement, too little combat wound information being considered, and the system

34 only suitable for on-site rescue. As the techniques involved in subsequent specialist treatment are complex,

35 the 37 items cannot fully characterize the injury. In China, there are other combat wound diagnostic code

36 studies that are mainly used for database construction in medical institutions, but the results are not well

37 suited for implementation in wound treatment during combat ${ }^{\mathbf{L}, 5,6 \mathbf{1}}$.

38 Related international standards include the International Classification of Diseases (ICD), which assigns a

39 unique alphanumeric code for disease classification and description. However, the ICD codes were

40 developed for the description of general diseases and do not quantify trauma severity, fully describe combat

41 wounds, or cover the complex injuries seen in the modern battlefield or combat wounds caused by new

42 weapons $^{\mathbf{6} 71}$. The 2005 Abbreviated Injury Scale (AIS) was developed by the US Association for the

43 Advancement of Automotive Medicine and is a simple method for triaging injuries based on severity. These

44 classification codes mostly cover common diseases and road traffic injuries. Therefore, the accuracy of 
45 these codes cannot be guaranteed when applied to combat wounds. Although some codes for penetrating

46 injuries were subsequently added, these are related to low-energy weapons and are not suitable for combat

47 wounds caused by high-energy weapons ${ }^{\mathbf{1 8 1}}$. In addition, the AIS is a non-continuous coding system and

48 its body regions are not fully based on anatomical classification, so the defined body regions are incomplete.

49 No codes are available for burns, large-area soft tissue injuries, or bilateral limb injuries ${ }^{\mathrm{Ig} 1}$.

50 The US army has two important combat wound classification systems, namely the deployable medical

51 system patient condition codes (PC-codes) ${ }^{[101}$ and the Military Combat Injury Scale (MCIS) ${ }^{[111}$. The PC-

52 codes integrate all descriptions of specific combat wounds into a whole and mainly originate from previous

53 war casualty data without referencing unified medical codes. Thus, the PC-codes are used for casualty

54 statistics during combat as well as post-combat analysis and simulation ${ }^{[12]}$. The MCIS code system is a set

55 of anatomy-based combat wound rating code standards that was constructed by an American field surgeon

56 expert team in November 2008. This system assigns a specific code to every combat injury or a group of

57 combat wounds with similar descriptions ${ }^{[13]}$. This system was constructed after compiling a large volume

58 of historical combat wound data and comparison between combat wounds and modern civilian trauma

59 code systems. The main problems associated with these codes are that the descriptions are overly general

60 and there is no unified combat wound classification axis or severity grading. Therefore, they are not suitable

61 for the coding of actual combat wound data and cannot describe changes in an injured person's condition

$62 \sqrt{14,151}$. During the Iraq War, the US army used PC-codes for preliminary statistical analysis of casualties

63 at the emergency treatment stage and re-analysis using ICD-9-CM was carried out after the casualties

64 reached the field hospital. However, as the criteria for these two systems are different, the information

65 cannot be effectively converted and around $10 \%$ of casualty data had to be discarded ${ }^{\mathrm{I} 101}$.

66 Currently, combat wound treatment in the Chinese PLA follows the principles of triaged treatment. 
67 According to the current Regulations on Combat Wound Rescue, The period from the battlefield treatment

68 to the rear hospital treatment is divided into three stages: battlefield on-site first aid, emergency treatment,

69 and early treatment. Battlefield on-site first aid is usually performed by medics and company/battalion

70 resuscitation teams where the scope of techniques applied includes ventilation, hemostasis, bandaging,

71 immobilization, transportation, and basic life support. In the second stage, emergency treatment is usually

72 performed by the brigade (regiment) medical station and techniques include wound inspection and

73 classification, treatment of comatose casualties, treatment of casualties with pneumothorax, emergency

74 treatment of eyeball rupture, encephalocele, bowel prolapse, emergency treatment of spinal injuries,

75 management of large burn areas, shock control, and infection control. Third stage early treatment is usually

76 performed by the mobile medical service and the scope of techniques includes emergency surgery,

77 controlled surgery, debridement, blood transfusion, fluid infusion, and oxygen inhalation. Casualties enter

78 the specialist treatment stage on arrival at the hospital and comprehensive definitive surgery, functional

79 restorative surgery, and plastic surgery are carried out ${ }^{[11}$.

80 This study focuses on the differential treatment needs of combat wound casualties at the three treatment

81 stages which are used as a framework to design an expandable combat wound classification coding system

82 to support triage according to the treatment echelon. On this basis, in order to determine which combat

83 wounds are high-incidence fatal injuries and which casualties in different treatment stages require more

84 attention, this set of combat wound classification codes was used for clustering analysis to screen for high-

85 incidence fatal injuries at different treatment stages ${ }^{[16]}$, and a stratified standardized combat wound injury

86 spectrum based on triaged treatment was constructed. This provides a reference for the timely and effective

87 triaged treatment of combat casualties.

88 2. METHODS

$89 \quad 2.1$ Design of combat wound classification codes 
90 Combat wound classification is essentially composed of 5 components: injury site, cause of injury, injury

91 type, injury severity, and combat wound complications ${ }^{[17]}$. The three-tiered treatment echelon of battlefield

92 on-site first aid, emergency treatment, and early treatment was used as a framework to expand the combat

93 wound classifications for a total of 454 combat wound data items to reflect the characteristics of treatment

94 tasks at each stage, as treatment skill level increases with deepening treatment echelon, and changes in

95 injury severity vary with time and treatment measures.

96 2.2. Design of injury spectrum statistical indicators

97 The injury spectrum was designed based on combat wound classification codes. The likelihood of a combat

98 wound being encountered during on-site first aid, the importance of casualty treatment during the

99 emergency treatment phase, and the operability and adaptability of a treatment measure during the early

100 treatment stage were used as bases to design the three-dimensional indicators: likelihood, importance, and

101 suitability. A 5-point scoring system was developed where the higher the score, the better the effects of that

102 indicator $^{\mathbf{1} 18,19 \mathbf{1}}$.

\section{$103 \quad 2.3$ Survey subjects}

104 For expert selection, in consideration of regional differences, we selected one theater command general

105 hospital from each of the north, south, east, and west, as well as central theater commands. In consideration

106 of the differences between the military branches, one affiliated hospital each from the Army Medical

107 University, Naval Medical University, and Air Force Medical University was selected. The People's

108 Liberation Army General Hospital that covers the entire army was also selected, making a total of 9

109 hospitals. One clinician with a vice-senior or higher professional title was selected from each of the

110 following: the emergency department, general surgery department, and critical care medicine department

111 of each hospital, making a total of 27 experts. The selected experts each had more than 10 years of clinical

112 practice experience. A portion of subjects (37\%) were the chief or deputy-chief of their department. Most 
113 experts were from general surgery or emergency departments, with 9 subjects each and accounting for $66.7 \%$

114 of all experts. Other experts included 3 from an orthopedics department, 2 from the department of critical

115 care medicine, and 1 each from thoracic surgery, spinal surgery, and anorectal surgery departments. The

116 majority of the experts (70\%) were core members of a hospital field medical team (center), with extensive

117 practical and research experience, and were considered to be authoritative.

\section{$118 \quad 2.4$ Survey process}

119 One pilot survey and 2 full surveys were conducted in this study. A meeting was held for the pilot survey

120 in which one field surgery expert and one medical logistics expert completed the questionnaire and made

121 an assessment of its rationality, clarity, and objectivity. The questionnaires were revised according to the

122 opinions of the two experts to generate a final questionnaire ${ }^{\mathbf{I} 20 \mathbf{I}}$. In the full survey, the Delphi method was

123 employed, and questionnaires were sent to the 27 experts who were asked to provide quantitative values

124 for each indicator. The results of the first full survey were used to assign one reference value for every

125 indicator, which was taken as a reference for the second full survey so that the overall results were more

126 focused. The expert scores of the second full survey were taken as the final results ${ }^{\mathbf{I} 1 \mathbf{I}}$. In order to ensure

127 the engagement of the experts in participating in the consultation, and to control the duration of the 128 consultation, staff were assigned to carry out close telephone communication with the experts when the 129 questionnaires were distributed to ensure that no questions were missed and no significant errors were made.

130 This also shortened the response time and ensured the quality of the consultation results.

\section{$131 \quad 2.5$ Data processing}

132 The statistical methods used for the analysis of the general expert questionnaire include stratified analysis, 133 principal component analysis, indicator threshold method, and Colaizzi’s method of content analysis ${ }^{\mathbf{\complement} 2,23 \mathbf{~}}$.

134 As this questionnaire has a structured format, qualitative analysis methods were not suitable. Also, since 135 the survey contained a significant volume of content, stratified analysis was not suitable for pairwise 
136 comparative analysis. In addition, there is a need to analyze the concentration of opinions and interactions

137 between the three-dimensional indicators of likelihood, importance, and suitability for combat wound

138 classification codes. Therefore, the Herfindahl-Hirschman Index (HHI) was used as a reference. This index

139 was used by the United States Department of Justice to assess the level of concentration within industries

$140 \quad{ }^{\mathbf{2} 41}$. The formula is

$$
H H I=\sum_{i=1}^{N}\left(\frac{X_{i}}{X}\right)^{2}=\sum_{i=1}^{N} S_{i}^{2}
$$

142 where $\mathrm{X}$ represents the whole scale of all study object indicators, $\mathrm{Xi}$ is one specific study object indicator,

$143 \mathrm{Si}=\mathrm{Xi} / \mathrm{X}$ is the share of the ith object in the entire scale, and $\mathrm{N}$ represents the total number of objects. The

144 greater the HHI index, the more concentrated the industry is and the greater the degree of monopoly it has.

145 The lower the HHI is, the more diverse is the market. We adjusted and optimized these parameters so that

146 they reflect the dispersion of likelihood, importance, and suitability of the various factors in combat wound

147 classification and so reflect the differences in the levels of these three indicators, which were recorded as

148 the quasi-HHI index. After the injury spectrum ranking was obtained by using the quasi-HHI index, we

149 used threshold values to screen for injuries that the require most urgent attention at the various treatment

150 stages ${ }^{\mathrm{I} 25 \mathrm{I}}$. The specific calculation method for the quasi-HHI index is as follows:

$$
H I_{\text {like }}=\sum_{i=1}^{n}\left(\frac{x_{i}}{10} \cdot 100\right)^{2} .
$$

\section{3. RESULTS}

\section{$153 \quad 3.1$ Reliability analysis of statistical results}

154 According to their own self-assessment, the expert's familiarity in this survey Cs was 0.923 and 155 authoritativeness $\mathrm{Cr}$ was 0.946 . Therefore, the results can be considered to be reliable. In this study, 54 156 questionnaires were distributed in two rounds, and all questionnaires were found to be valid. Hence, the 
157 valid questionnaire recovery rate was $100 \%$. In this survey, the reliability coefficients of the scales were all

158 above 0.7 and highest reliability was 0.833 . The normality test for the index scores of the expert surveys

159 showed that the skewness was 0.184 , which is close to 0 ; the kurtosis was -0.459 , which is significantly

160 less than 0 . The scores showed a sharp peak in their distribution, reflecting consensus among expert

161 opinions $^{[26]}$.

\section{$162 \quad 3.2$ Injury spectrum statistical results based on combat wound classification codes}

\section{$163 \quad 3.2 .1$ Injury site analysis}

164 The focus of treatment at the battlefield on-site first aid stage is on maintenance of vital signs and rapid

165 evacuation of casualties, so only preliminary evaluation of the patient's condition is carried out and the

166 classification of injuries is simplified. Therefore, a 2-digit code was used to indicate 9 body sites at the

167 battlefield on-site first aid stage and likelihood indicators in the expert consultation questionnaires were

168 used. The coefficient of variation of likelihood scores given by the experts were within 0.3 , indicating good

169 coordination and consistency in expert opinions. Table 1 shows the results.

Table 1 Injury site likelihood indicators at the battlefield on-site first aid stage

\begin{tabular}{llccc}
\hline \multirow{2}{*}{$\begin{array}{l}\text { Injury site code } \\
\text { Name of injury site }\end{array}$} & Likelihood & $\begin{array}{c}\text { Coefficient of } \\
\text { variation }\end{array}$ & Pi \\
\hline 01 & Head (brain) & 8.11 & 0.15 & 0.11 \\
02 & Face & 8.44 & 0.15 & 0.07 \\
03 & Neck & 7.67 & 0.21 & 0.05 \\
04 & Chest (back) & 8.50 & 0.13 & 0.14 \\
05 & Abdomen (waist) & 8.38 & 0.11 & 0.17 \\
06 & Pelvis (perineum) & 7.50 & 0.22 & 0.03 \\
07 & Spine and spinal cord & 7.06 & 0.29 & 0.02 \\
08 & Upper limbs & 7.94 & 0.15 & 0.15 \\
09 & Lower limbs & 8.11 & 0.15 & 0.26 \\
\hline
\end{tabular}

171

172 The injury site code at the emergency treatment stage is a 4-digit number that permits expansion from the

1739 body site codes from the battlefield stage to include 62 anatomical structures in total. The quasi-HHI 
174 index was used for normalization and combining of the original qualitative indicators (likelihood,

175 importance, and suitability) and is used as a key indicator for injury spectrum ranking. The arithmetic mean

176 plus standard deviation was used to calculate the high priority indicator cutoff and the arithmetic mean

177 minus standard deviation was used to calculate the low priority indicator cutoff. The high priority indicator

178 cutoff was used to select 15 anatomical structures for attention at the emergency treatment stage and their

179 body sites. Table 2 shows the results.

180 We further expanded the 62 body sites at the emergency treatment stage to 268 injury sites that are

181 considered in the early treatment stage. By calculating a high priority indicator cutoff, we selected the top

18220 injury sites in the quasi-HHI index ranking, from 6 injury site codes at the early treatment stage. Table

$183 \quad$ 3 shows the results.

\section{$184 \quad$ 3.2.2 Combat wound complication analysis}

185 We calculated the quasi-HHI indices over the three-tiered treatment echelon to obtain the final ranking of

18661 combat wound complications in the various treatment stages and calculated the high priority indicator

187 cutoff to obtain the top 10 combat wound complications, which is shown in Table 4.

\section{4. CONCLUSION}

189 After the combat wound classification codes were designed, we evaluated their practical efficacy in a series

190 of medical logistics exercises. During the evaluation, we selected two battalion/company rescue teams at

191 different time periods to test the use of the classification codes at the battlefield on-site first aid stage. We

192 also selected two brigade treatment sites to evaluate the use of the classification codes at the emergency

193 treatment stage. Within the environment of base training of the mobile medical logistic teams, two field

194 medical teams were selected over different time periods to examine the application of the classification

195 codes at the early treatment stage, focusing on the criteria of coding speed, coding accuracy, and

196 connectivity after the combat wound information was transferred to the specialist hospitals ${ }^{[27]}$. 
197 Eighteen standard casualties were set up according to a 3:2:1 ratio of mild, moderate, and severe wounds, 198 respectively. The battalion/company rescue teams first used traditional injury tickets for casualty 199 classification, then they used our classification code for the task. After this, the teams underwent two 200 sessions of training before using our classification code. Due to the lack of standardized casualty 201 classification procedures at the emergency treatment and early treatment stages, staff at the brigade 202 treatment sites, and the field medical teams were requested to describe injuries based on the general medical 203 treatment standards. Following that, two rounds of casualty classification using our codes were carried out, 204 one before and one after training. The mean coding time for the 18 casualties was measured at different 205 treatment institutions, the results of which are shown in Figure 1.

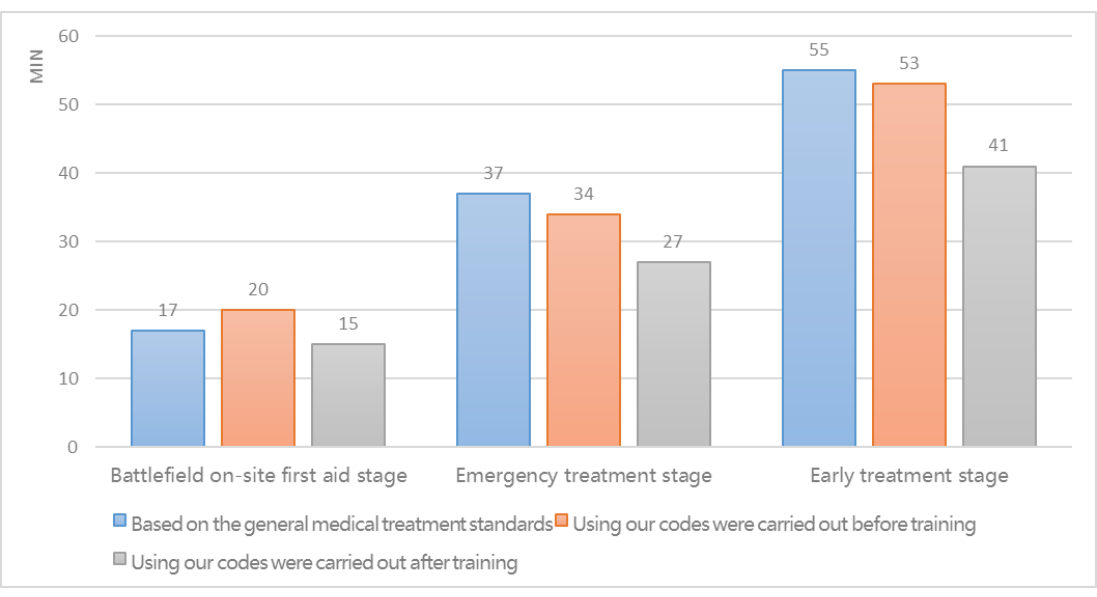

Figure 1. Time needed for casualty classification

208 Expert surgeons then assessed whether the casualty classification was carried out correctly at each treatment 209 site. The results are shown in Figure 2. 


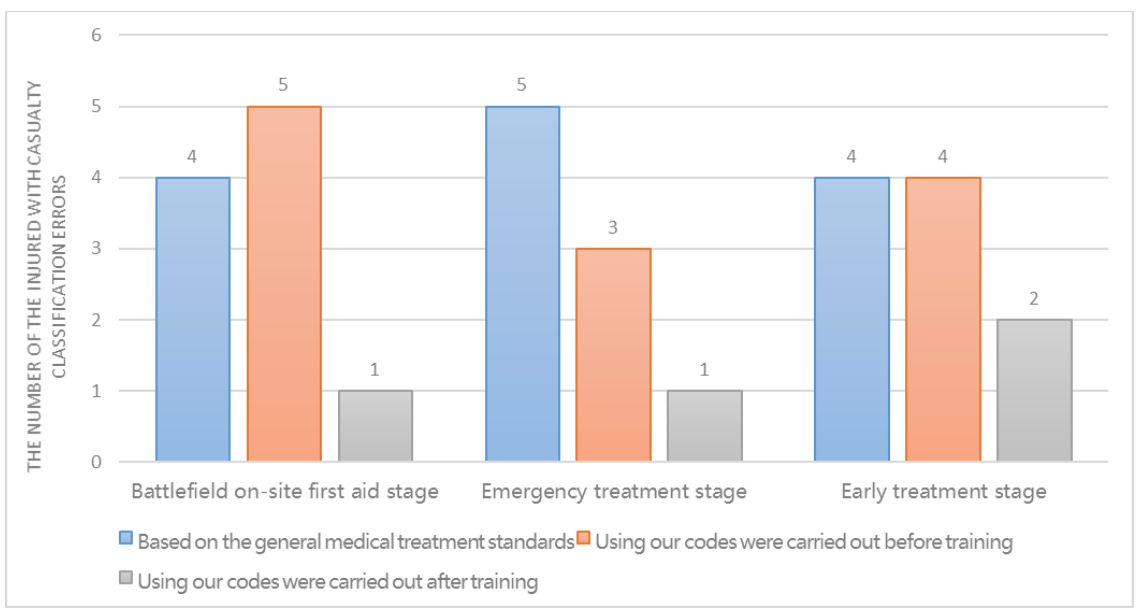

Figure 2. Casualty classification errors

212 Compared with traditional methods, the time spent on coding was reduced and classification accuracy was

213 improved when using our codes. We further analyzed the classification status of early treatment stage

214 casualties. After casualties that were classified according to the conventional method reached the rear

215 hospitals, the classification of 9 out of 36 casualties treated by the two field medial teams could not be

216 reused because the combat wound information was not standardized and this required the hospital to re-

217 classify and fill in relevant medical documents. In contrast, as our classification method considered the

218 connection between pre-hospital casualty treatment and hospital treatment, the classification results of all

21936 casualties could be reused. This greatly improved the efficiency of classification, reduced the workload

220 of hospital staff, and ensured that the injury information was intact and continuous.

221 The injury spectrum was comprehensively analyzed and sorted according to the scores given by the experts,

222 the quasi-HHI index of hemorrhage was ranked 1st in battlefield on-site first aid, and emergency treatment

223 stages and 2nd in the early treatment stage. Hemorrhagic shock was ranked 3rd in the battlefield on-site

224 first aid, and emergency treatment stages, and 1st at the early treatment stage. This concentration reflects

225 the great deal of attention paid by military field surgeons of the Chinese PLA on hemorrhage during combat 226 wound treatment. Analysis of previous combat data also supported this viewpoint. The combined statistics 
227 of the military history of the Chinese PLA showed that $50 \%$ of combat wound deaths were due to

228 hemorrhage at the limbs, $10 \%$ of soldiers killed in action resulted from trunk and visceral hemorrhage,

229 while $9 \%$ of deaths were due to hemorrhage from all 4 limbs. At the Battle of Triangle Hill in the Korean

230 War, $32 \%$ of 1136 deaths from the 45th division were due to hemorrhage. In the Sino-Vietnamese War,

$23150 \%$ of deaths at the regimental medical station were caused by hemorrhage and shock ${ }^{\mathbf{L} 28 \mathbf{1}}$.

232 In terms of the quasi-HHI index, asphyxiation was ranked 2nd, after only hemorrhage, and requires a great

233 deal of attention and immediate treatment by company/battalion emergency medical staff. Past combat data

234 from the Chinese PLA show that respiratory problems caused by coma, inhalation injuries, chemical

235 injuries, severe impact, and direct airway injury account for 5-10\% of total casualties, and are the 2 nd most

236 important reason for mortality ${ }^{\mathbf{L} 21}$.

237 The quasi-HHI index for tension pneumothorax is ranked 4th at the battlefield on-site first aid stage and 7th

238 at the emergency treatment stage, while the quasi-HHI indices of open pneumothorax and

239 hemopneumothorax were also ranked in the top 10 for these two treatment stages. Relevant papers showed

240 that the mean time to death for tension pneumothorax and hemothorax is $25-40$ minutes ${ }^{\mathbf{I} 301}$. Hence, these

241 injuries are one of the major causes of rapid death in battlefield casualties.

\section{5. Discussion}

243 Based on the results of this study, the combat wound experts of the Chinese PLA have established a " 3

244 rapid and 3 strengthening" concept for combat triage involving: rapid control of life-threatening

245 hemorrhage, rapid administration of life support, and rapid injury control, as well as strengthening the

246 integration between medical logistics and combat, strengthening timely treatment, and strengthening

247 triaged treatment connections. In addition, they have established a new policy of "three points and one chain"

248 consisting of: rapid early stage, precise intermediate stage, and strong late stage for treatment measures. We

249 also developed a new spinning tourniquet, and compressed gauze, which significantly improve the 
250 reliability of self-treatment and mutual treatment of hemorrhage and the hemostasis of life-threatening 251 hemorrhage, particularly the problem of hemostasis at junctions. Our study drives the early implementation 252 of fluid resuscitation, airway management, and closed chest drainage, which provide safe and effective 253 measures, and technical support for frontline medical treatment ${ }^{\mathbf{t} 311}$.

254 Here are still some limitations in this study, mainly embodied in as follows. In the detection of the 255 practical application effect of combat wound classification code, 2 of the 3 types of treatment 256 institutions: battlefield on-site first aid, emergency treatment, and early treatment, were selected, 257 respectively, and classification and coding experiment of the combat wounded was carried out only once 258 for each combat wound classification method. The size of experimental subjects and the number of 259 experiments are too small, which may have certain influence on the detection of practical effect. In the next 260 step, this study intends to further expand the application range in the army, and improve the application 261 according to the situation of the army, so as to enhance the practical effect of the study. Moreover, the 262 current relevant academic viewpoints suggest to add a technical link related to surgical resuscitation 263 between the emergency treatment and early treatment of the level II treatment ladder of combat wound.

264 This study should also pay close attention to the changes in this new situation, and fine-tune the 265 location, structure and application objects of some combat wound codes, so that the study can 266 adapt to the new needs of combat and health service support. 
Table 2. Top 15 injury sites by quasi-HHI index at the emergency treatment stage

\begin{tabular}{|c|c|c|c|c|c|c|c|c|c|}
\hline \multirow{2}{*}{$\begin{array}{c}\text { Injury } \\
\text { site } \\
\text { code }\end{array}$} & \multirow{2}{*}{$\begin{array}{c}\text { Name of injury } \\
\text { site }\end{array}$} & \multirow{2}{*}{$\begin{array}{c}\text { Injury site code } \\
\text { of the level } \\
\text { above }\end{array}$} & \multicolumn{2}{|c|}{ Likelihood indicator } & \multicolumn{2}{|c|}{ Importance indicator } & \multicolumn{2}{|c|}{ Suitability indicator } & \multirow{2}{*}{$\begin{array}{l}\text { HHI } \\
\text { Index }\end{array}$} \\
\hline & & & Mean & $\begin{array}{c}\text { Coefficient of } \\
\text { variation }\end{array}$ & Mean & $\begin{array}{c}\text { Coefficient of } \\
\text { variation }\end{array}$ & Mean & $\begin{array}{c}\text { Coefficient of } \\
\text { variation }\end{array}$ & \\
\hline 0302 & $\begin{array}{l}\text { Throat and } \\
\text { trachea }\end{array}$ & 03 Neck & 7.96 & 0.16 & 8.91 & 0.05 & 7.64 & 0.20 & 2.01 \\
\hline 0304 & $\begin{array}{l}\text { Neck blood } \\
\text { vessels }\end{array}$ & 03 Neck & 7.70 & 0.18 & 8.91 & 0.05 & 7.27 & 0.24 & 1.92 \\
\hline 0506 & Spleen & $\begin{array}{l}05 \text { Abdomen } \\
\text { (waist) }\end{array}$ & 7.68 & 0.17 & 8.57 & 0.09 & 7.48 & 0.23 & 1.88 \\
\hline 0505 & Hepatic & $\begin{array}{l}\text { 05 Abdomen } \\
\text { (waist) }\end{array}$ & 7.73 & 0.17 & 8.57 & 0.09 & 7.29 & 0.19 & 1.86 \\
\hline 0403 & Thoracic cavity & 04 Chest (back) & 7.96 & 0.19 & 7.64 & 0.17 & 7.36 & 0.25 & 1.76 \\
\hline 0404 & Lungs & 04 Chest (back) & 7.82 & 0.17 & 8.18 & 0.12 & 6.90 & 0.24 & 1.76 \\
\hline 0105 & Scalp & 01 Head (brain) & 8.39 & 0.20 & 6.30 & 0.30 & 8.09 & 0.16 & 1.76 \\
\hline 0405 & $\begin{array}{l}\text { Trachea and } \\
\text { bronchi }\end{array}$ & 04 Chest (back) & 7.41 & 0.22 & 8.27 & 0.14 & 6.86 & 0.28 & 1.70 \\
\hline 0906 & $\begin{array}{l}\text { Lower limb } \\
\text { blood vessels }\end{array}$ & 09 Lower limbs & 7.17 & 0.23 & 8.45 & 0.15 & 6.81 & 0.25 & 1.69 \\
\hline 0807 & $\begin{array}{l}\text { Upper limb } \\
\text { blood vessels }\end{array}$ & 08 Upper limbs & 7.13 & 0.22 & 8.52 & 0.13 & 6.64 & 0.38 & 1.68 \\
\hline 0901 & Thigh & 09 Lower limbs & 7.96 & 0.15 & 7.36 & 0.21 & 6.90 & 0.26 & 1.65 \\
\hline 0510 & $\begin{array}{l}\text { Abdominal } \\
\text { blood vessels }\end{array}$ & $\begin{array}{l}\text { 05 Abdomen } \\
\text { (waist) }\end{array}$ & 6.95 & 0.24 & 8.73 & 0.08 & 6.19 & 0.41 & 1.63 \\
\hline 0903 & Calf & 09 Lower limbs & 8.13 & 0.16 & 7.09 & 0.20 & 6.71 & 0.26 & 1.61 \\
\hline 0509 & $\begin{array}{l}\text { Abdominal } \\
\text { cavity }\end{array}$ & $\begin{array}{l}05 \text { Abdomen } \\
\text { (waist) }\end{array}$ & 7.95 & 0.25 & 7.19 & 0.21 & 6.80 & 0.24 & 1.61 \\
\hline 0603 & Pelvic bone & $\begin{array}{l}06 \text { Pelvis } \\
\text { (perineum) }\end{array}$ & 7.61 & 0.18 & 7.36 & 0.25 & 6.73 & 0.24 & 1.57 \\
\hline
\end{tabular}


Table 3. Top 20 injury sites by quasi-HHI index at the early treatment stage

\begin{tabular}{|c|c|c|c|c|c|c|c|c|c|}
\hline \multirow{2}{*}{$\begin{array}{l}\text { injury } \\
\text { site code }\end{array}$} & \multirow{2}{*}{ Name of injury site } & \multirow{2}{*}{$\begin{array}{c}\text { Injury site code } \\
\text { of the level } \\
\text { above }\end{array}$} & \multicolumn{2}{|c|}{$\begin{array}{l}\text { Likelihood } \\
\text { indicator }\end{array}$} & \multicolumn{2}{|c|}{ Importance indicator } & \multicolumn{2}{|c|}{ Suitability indicator } & \multirow{2}{*}{$\begin{array}{l}\text { HHI } \\
\text { Index }\end{array}$} \\
\hline & & & Mean & $\begin{array}{l}\text { Coefficient } \\
\text { of variation }\end{array}$ & Mean & $\begin{array}{c}\text { Coefficient of } \\
\text { variation }\end{array}$ & Mean & $\begin{array}{c}\text { Coefficient of } \\
\text { variation }\end{array}$ & \\
\hline 030202 & $\begin{array}{l}\text { Laryngeal } \\
\text { connection }\end{array}$ & $\begin{array}{l}0302 \text { Throat and } \\
\text { trachea }\end{array}$ & 8.13 & 0.42 & 8.48 & 0.12 & 8.30 & 0.11 & 2.07 \\
\hline 030402 & $\begin{array}{l}\text { External carotid } \\
\text { artery }\end{array}$ & $\begin{array}{l}0304 \text { Neck } \\
\text { blood vessels }\end{array}$ & 7.64 & 0.27 & 8.84 & 0.09 & 8.33 & 0.18 & 2.06 \\
\hline 030401 & $\begin{array}{l}\text { Common carotid } \\
\text { artery }\end{array}$ & $\begin{array}{l}0304 \text { Neck } \\
\text { blood vessels }\end{array}$ & 7.40 & 0.27 & 8.84 & 0.09 & 8.33 & 0.18 & 2.02 \\
\hline 040302 & Pleural cavity & $\begin{array}{l}0403 \text { Thoracic } \\
\text { surgery }\end{array}$ & 8.12 & 0.23 & 8.31 & 0.13 & 8.17 & 0.16 & 2.02 \\
\hline 030403 & $\begin{array}{l}\text { Internal carotid } \\
\text { artery }\end{array}$ & $\begin{array}{l}0304 \text { Neck } \\
\text { blood vessels }\end{array}$ & 7.24 & 0.25 & 8.84 & 0.09 & 8.25 & 0.20 & 1.99 \\
\hline 010201 & Epidural space & $\begin{array}{l}0102 \text { Cranial } \\
\text { cavity }\end{array}$ & 7.96 & 0.25 & 8.44 & 0.16 & 7.75 & 0.24 & 1.95 \\
\hline 030205 & Neck trachea & $\begin{array}{l}0302 \text { Throat and } \\
\text { trachea }\end{array}$ & 8.04 & 0.25 & 8.36 & 0.15 & 7.75 & 0.19 & 1.95 \\
\hline 030406 & $\begin{array}{l}\text { Internal jugular } \\
\text { vein }\end{array}$ & $\begin{array}{l}0304 \text { Neck } \\
\text { blood vessels }\end{array}$ & 7.24 & 0.20 & 8.60 & 0.11 & 8.17 & 0.20 & 1.93 \\
\hline 030404 & $\begin{array}{l}\text { External jugular } \\
\text { vein }\end{array}$ & $\begin{array}{l}0304 \text { Neck } \\
\text { blood vessels }\end{array}$ & 7.64 & 0.24 & 8.12 & 0.14 & 8.08 & 0.20 & 1.90 \\
\hline 050502 & Right lobe & 0505 Liver & 7.71 & 0.24 & 8.29 & 0.13 & 7.70 & 0.21 & 1.87 \\
\hline 030407 & $\begin{array}{l}\text { Blood vessels at } \\
\text { the root of the neck }\end{array}$ & $\begin{array}{l}0304 \text { Neck } \\
\text { blood vessels }\end{array}$ & 7.08 & 0.26 & 8.58 & 0.12 & 7.96 & 0.19 & 1.87 \\
\hline 010101 & Frontal bone & 0101 Skull & 7.75 & 0.24 & 7.75 & 0.22 & 7.78 & 0.24 & 1.81 \\
\hline 030201 & Laryngeal cartilage & $\begin{array}{l}0302 \text { Throat and } \\
\text { trachea }\end{array}$ & 7.64 & 0.42 & 8.04 & 0.16 & 7.50 & 0.18 & 1.79 \\
\hline 050601 & Splenic hilum & 0506 Spleen & 7.21 & 0.20 & 8.38 & 0.11 & 7.52 & 0.22 & 1.79 \\
\hline 050501 & Left lobe & $\begin{array}{l}\text { 0505 Liver } \\
0906 \text { Lower }\end{array}$ & 7.29 & 0.23 & 8.13 & 0.14 & 7.70 & 0.21 & 1.78 \\
\hline 090604 & Popliteal artery & $\begin{array}{l}\text { limb blood } \\
\text { vessels }\end{array}$ & 6.76 & 0.22 & 8.52 & 0.12 & 7.67 & 0.18 & 1.77 \\
\hline 040403 & Lower lobe & 0404 Lung & 7.32 & 0.24 & 8.12 & 0.16 & 7.58 & 0.22 & 1.77 \\
\hline 090101 & Femur & 0901 Thigh & 7.64 & 0.21 & 7.72 & 0.14 & 7.67 & 0.19 & 1.77 \\
\hline 050602 & Splenic artery & $\begin{array}{l}0506 \text { Spleen } \\
0906 \text { Lower }\end{array}$ & 7.13 & 0.20 & 8.46 & 0.10 & 7.35 & 0.24 & 1.76 \\
\hline 090603 & Femoral artery & $\begin{array}{l}\text { limb blood } \\
\text { vessels }\end{array}$ & 6.60 & 0.18 & 8.60 & 0.11 & 7.67 & 0.18 & 1.76 \\
\hline
\end{tabular}


Table 4. Top 10 combat wounds by HHI index in the three-tiered treatment echelon

\begin{tabular}{llcccccc}
\hline \multirow{2}{*}{$\begin{array}{c}\text { injury } \\
\text { site code }\end{array}$} & \multicolumn{1}{c}{ Name of complication } & \multicolumn{2}{c}{$\begin{array}{c}\text { Battlefield on-site first } \\
\text { aid stage }\end{array}$} & \multicolumn{2}{c}{$\begin{array}{c}\text { Emergency treatment } \\
\text { stage }\end{array}$} & \multicolumn{2}{c}{ Early treatment stage } \\
\cline { 3 - 8 } & & HHI index & Rank & HHI index & Rank & HHI index & Rank \\
\hline 02 & Hemorrhage & 2.27 & 1 & 2.26 & 1 & 2.23 & 2 \\
04 & Asphyxiation & 2.15 & 2 & 2.19 & 4 & 2.08 & 9 \\
14 & Hemorrhagic shock & 2.11 & 3 & 2.22 & 3 & 2.27 & 1 \\
51 & Tension pneumothorax & 2.10 & 4 & 2.10 & 7 & 2.01 & 13 \\
15 & Traumatic shock & 2.07 & 5 & 2.26 & 2 & 2.23 & 3 \\
50 & Open pneumothorax & 2.02 & 6 & 2.10 & 8 & 1.98 & 16 \\
16 & Burn shock & 2.00 & 7 & 2.17 & 5 & 2.18 & 5 \\
03 & Coma & 1.97 & 8 & 2.11 & 6 & 2.21 & 4 \\
53 & Hemopneumothorax & 1.73 & 9 & 2.03 & 10 & 1.96 & 15 \\
52 & Hemothorax & 1.73 & 10 & 2.03 & 9 & 1.98 & 17 \\
21 & Acute respiratory distress syndrome & 1.17 & 13 & 1.78 & 17 & 2.18 & 6 \\
12 & Sepsis & 1.01 & 36 & 1.59 & 26 & 2.06 & 10 \\
24 & Multiple organ dysfunction syndrome after & 0.97 & 38 & 1.44 & 36 & 2.10 & 7 \\
& combat wound & & & & & & \\
37 & Intracranial hematoma & 1.33 & 20 & 1.68 & 19 & 2.08 & 8 \\
\hline
\end{tabular}


273 Ethical Approval and Consent to participate

274 Not applicable

275 Consent for publication

276 Not applicable

277 Availability of data and materials

278 All the data involved in this paper are annotated in the references.

279 Competing interests

280 The authors declare that they have no competing interests.

281 Funding

282 Major Research Project of Chinese PLA Military Logistics (BWS14J04,AWS15J004,BWS14J041,

283 2015XL015,15WKS03)

284 Authors' contributions

285 Bo Peng wrote the article, and Zhen He and Tan-shi Li provided the idea. Shuo Liu and Fei Pan investigated 286 the Haddon matrix and screened and analyzed the data. All authors haveread and approved the final 287 manuscript.

288 Acknowledgements

289 Not applicable

290 Authors' information

291 Bo Peng, Ph.D., assistant research fellow, Institute of Health Service and Transfusion Medicine, Academy 292 of Military Medical Sciences,plapengbo@yeah.net

293 Shuo Liu, postgraduate, Institute of Health Service and Transfusion Medicine, Academy of Military 294 Medical Sciences

295 Fei Pan, Ph.D., head nurse, The First Medical Center of Chinese PLA General Hospital Emergency 
296 Department

297 Zhen He, Ph.D., associate research fellow/research director, Institute of Health Service and Transfusion 298 Medicine, Academy of Military Medical Sciences

299 Tan-shi Li, (Correspondent), Ph.D. chief physicians/director, The First Medical Center of Chinese PLA

300 General Hospital Emergency Department, li_tanshi@163.com 
1 Rules for the treatment of war injuries [M]. Beijing: General Logistics Department, Ministry of Health, 2006: 10-18

2 Institute of field surgery, Third Military Medical University. Classification and judgment criteria of war injuries: GJB 6032-2007 [S]. Beijing: General Logistics Department of the People's Liberation Army, 2007: 3

3 GJB 6032-2007, Classification and criterion of war wound[S].

4 PENG Bo, Kuai liping, DU Guo-fu, et al. Research on classification and coding system of conventional weapons combat injuries based on graded treatment [J]. People's Military Doctor, 2017, 60 (4): 350-351

5 International classification family cooperative center W.H.O., Peking Union Medical College Hospital. International statistical classification of diseases and related health problems, 10th revision, vol.1 [M]. Beijing: people's medical publishing house, 2008: 699-730

6 He YiGang. Research on diagnostic coding of war injuries [D]. Chongqing: Department of Plateau, Third Military Medical University, 2005

7 Raymond B. Devore, Catherine R. Stein, Barbara E. Wojcik. Patient Conditions and Associated ICD-9 Diagnosis

8 Zhou JiHong.Trauma Scoreology[M].Bejing:Science Press,2018:48-49.

$9 \mathrm{Hu}$, Pengwei and Chen, Fuxing, et al. Research process of combat injury coding of U.S. army [J]. Academic Journal of Second Military Medical University, 2017, 38(9): 1196-1201 10 WOJCIK B E, STEIN C R, DECORE Jr R B, HASSELL L H. The challenge of mapping between two medical coding systems[J]. Millitary Medicine ,2006,171:1128-1136.

11 Lawnick, Mary M. and Champion, Howard R., et al. Combat injury coding: A review and 
reconfiguration [J]. Journal of Trauma and Acute Care Surgery, 2013, 75(4): 573-581.

12 Shao, Wei and Li, Jiewei, et al. Investigation of the correlation of patient condition codes with medical supplies demand of the U. S. Armed forces [J]. Military Medical Sciences, 2016, 40(5): 422-424.

13 Mabry RL, Holcomb JB, Baker AM. United States Army Rangers in Somalia: An Analysis of Combat Casualties on an Urban Battlefield [J]. J Trauma, 2000, 49(3): 515-528

14 DEVORE Jr R B,STEIN C R,WOJCIK B E. Patient conditions and associated ICD-9 diagnosis codes [R].Army Medical Dept Center, School Fort Sam Houston Tx,2005:6-101.

$15 \mathrm{Hu}$, Pengwei and Chen, Fuxing, et al. Conversion between 2 military combat-related injury coding systems [J]. Medicine, 2018, 97(10).

16 Champion, Howard R. and Holcomb, John B., et al. Improved Characterization of Combat Injury [J]. Journal of Trauma-Injury Infection and Critical Care, 2010, 68(5): 1139-1150. 17 Peng Bo,Kuai liping,Zhang liqian, et al. The questionnaire consultation and analysis of the war wound spectrum of conventional weapons based on graded treatment [J]. People's Military Surgeon, 2008, 61 (10): 895-897.

18 Wang Shaona,Dong Rui,Xie Hui, et al. Application progress of Delphi method and its index system [J].Journal of Bengbu Medical College,2016,41(05):695-698.

19 Shi Liwen. SPSS 19.0 Statistical Analysis from Entry-level to Proficient [M]. Beijing. Tsinghua University Press. 2012: 336-337.

20 Fred. J. Fuller. Trans. Jiang Yimin. Design and evaluation of questionnaires [M]. Chongqing. Chongqing University Press, 2010

21 Liu Weitao,Gu Hong,Li Chunhong, et al. Expert evaluation method based on Delphi method [J]. Computer Engineering,2011,37(S1):189-191. 
22 Sun zhenqiu ,Xu yongyong.Medical Statistics[M].Beijing: People's Medical Publishing House,2012.

23 Webb C. Information point: Colaizzi's framework for analysing qualitative data.[J]. Journal of clinical nursing, 1999,8(5).

24 HHI(Herfindahl-Hirschman) Index Theory[J]. Modern Science \& Technology of Telecommunication, 2007(9):40-40.

25 Su Dongshui. Industrial Economics [M]. Beijing: Higher Education Press, 2000

26 Wang Zhouwei, Zhu Min. SPSS Statistical Analysis and Comprehensive Application.

Shanghai. Shanghai Jiao Tong University Press. 2012.

27 James M. Zouris, G. Jay Walker. Scenario-Based Projections of Wounded-in-Action Patient Condition Code Distributions [R]. San Diego: Naval Health Research Center, 2005 28 Pian Tao. Study on the diagnostic spectrum and coding standardization of five elements of war injury [D]. Third Military Medical University,2007:35

29 Chen Wenliang. Time-effect Treatment of Combat Injury[M].Beijing: Health Bureau of logistics support department of CMC,2019:23.

30 Han Ruiquan. The Development of Field First-aid Device of Tension Pneumothorax. [D]. Second Military Medical University,2008:10.

31 LI Tan-shi,FU Xiao-bing. Tactical combat casualty care-- from theory to practice [J]. Medical Journal of Chinese People's Liberation Army,2015,40(12):943-945. 
Figures

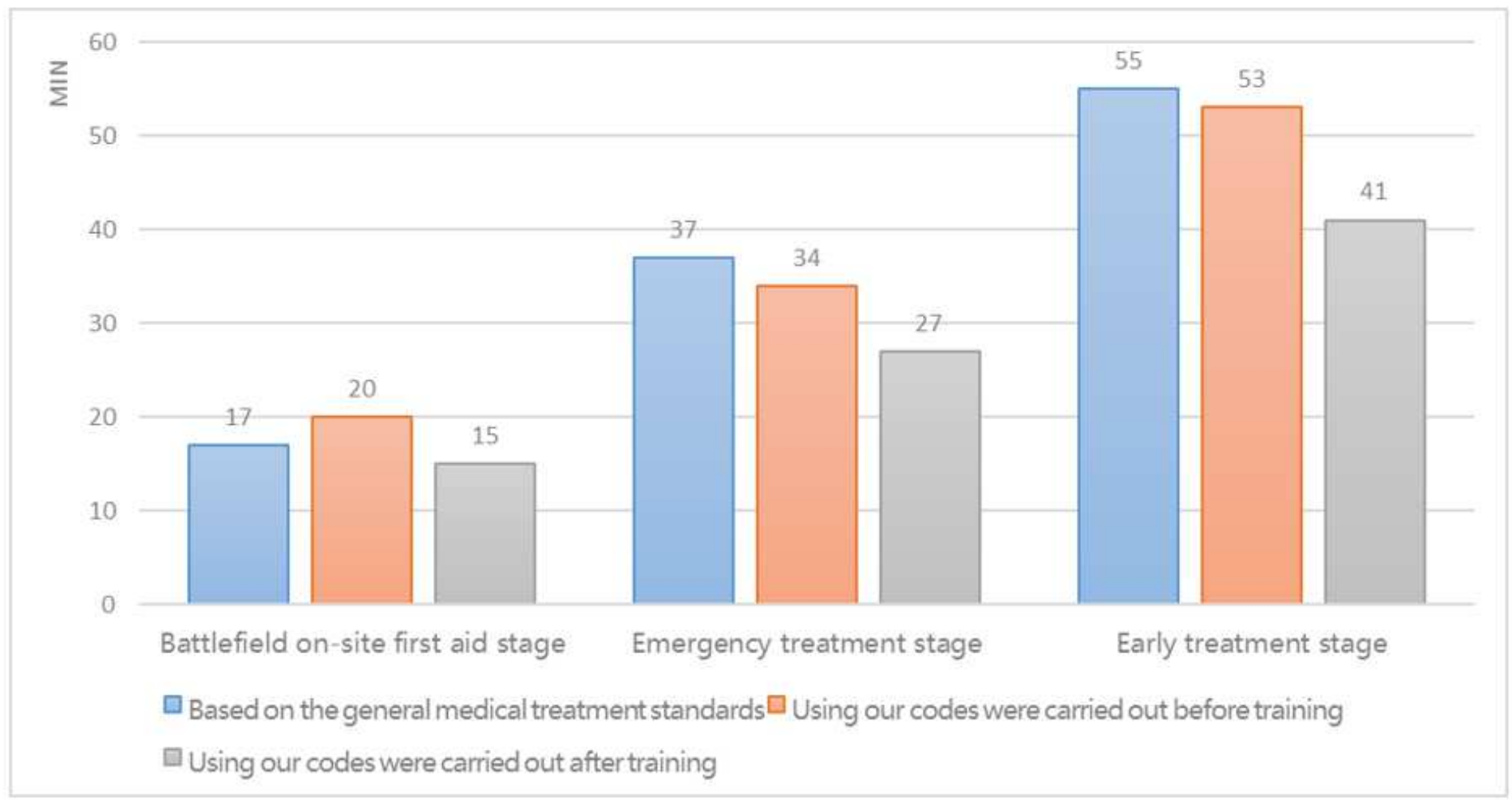

\section{Figure 1}

Time needed for casualty classification

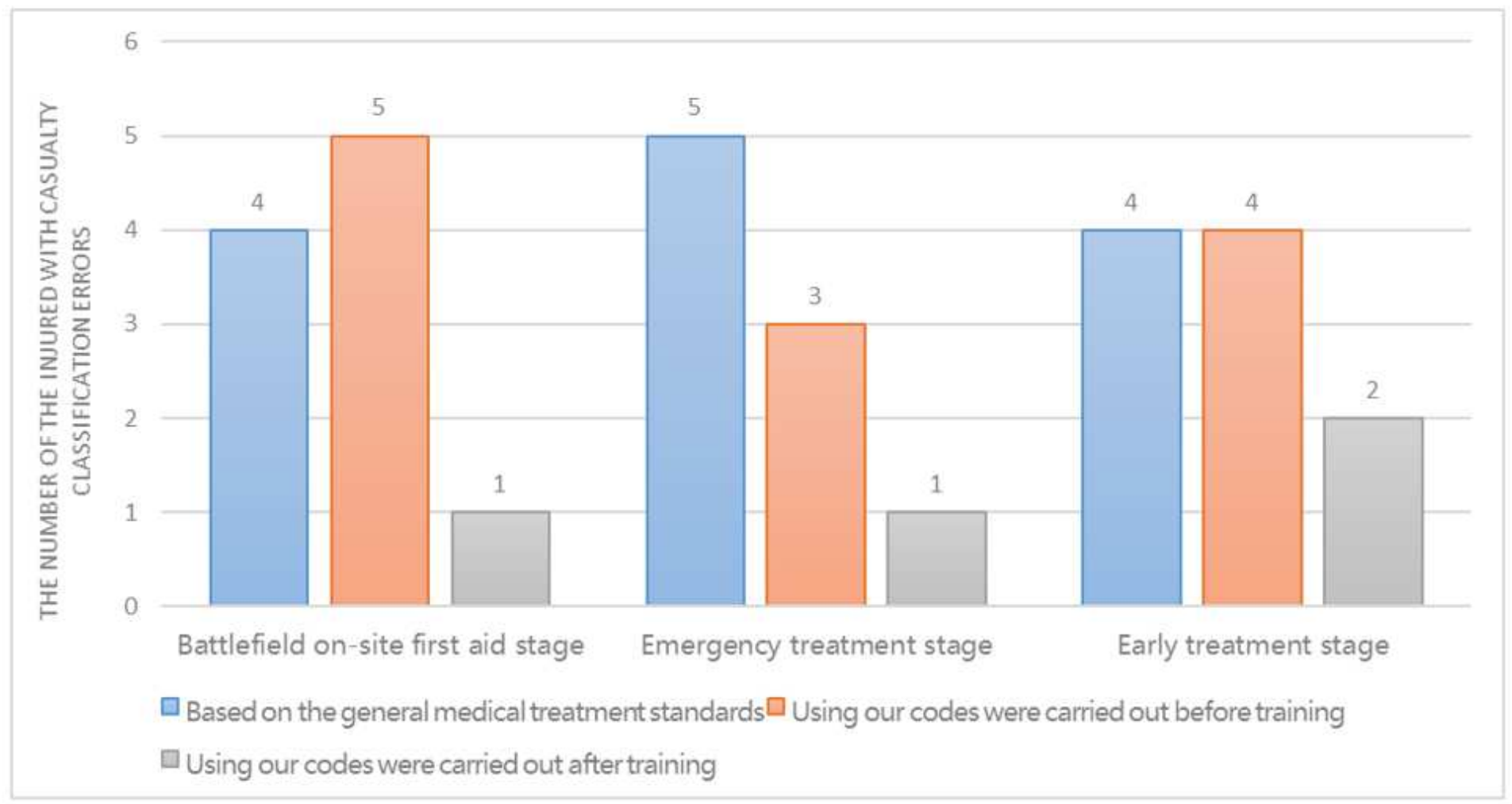


Figure 2

Casualty classification errors 